\title{
Subject Characteristics Result Standard Unit
}

National Cancer Institute

\section{Source}

National Cancer Institute. Subject Characteristics Result Standard Unit. NCI Thesaurus.

Code $C 83408$.

The standard unit of measure for subject characteristics results. 